\title{
The Development, Challenges and Vision of China's Educational Economics
}

\section{Cui Yichu}

Zhongnan University of Economics and Law, Hubei, Wuhan, 430073

\begin{abstract}
Keywords: development characteristics; challenges; opportunities and prospects; China's educational economics
\end{abstract}

\begin{abstract}
With the development of the times, the improvement of education quality has a positive effect on promoting the development of our country's economy and society. The effectiveness of educational economics is conducive to speeding up the transformation mode of economy and promoting the optimization and upgrading of industrial structure. At the same time, it can also improve the relationship between income and distribution, narrow the gap between the rich and the poor, and promote the healthy growth of our economy. The first part of this paper describes the development characteristics of educational economics in China, and analyzes its significance. The second part analyzes the challenges and difficulties encountered in the process of the development of China's educational economics, and the reasons for these problems. Finally, the future development of education economics in China is explored. In order to improve the scientificity and effectiveness of education economics and promote the healthy and sustainable development of China's economy, some related development measures have been put forward.
\end{abstract}

\section{The Development Characteristics of China's Educational Economics}

First of all, educational economics has certain practical value. The content of the study of educational economics can be combined with the actual needs of economic and social development. It is a subject of practical use. It can make concrete research on the important issues and provide many practical and active roles for the development of the economy and society. China's education economics has established its own unique perspective and issues, and the discipline has become more and more clear. It has formed an academic community with a certain scale. It is a very important subject among the educational circles of our country.

Secondly, the starting point of educational economics is higher. Many of the predecessors of the education economics of our country are scholars who have strong ability and knowledge in the academic circles. With the continuous development of education economics, they have also progressed to prove the preeminent thinking and excellent horizon of these pioneers. At the same time, the vigorous development of China's educational economics has also led to the development of other disciplines, and has brought positive significance to China's education [1].

Finally, the boundaries of educational economics are becoming increasingly unclear. As a cross subject, educational economics involves many fields. The content of the study is no longer only the field of education and economics. It has gradually been explored in a variety of disciplines, such as sociology, politics, management, and so on. With the continuous development of educational economics and the integration with other disciplines, the boundary of educational economics is becoming more and more unclear and the field of research is broader.

\section{The Challenges Encountered in the Development of China's Educational Economics.}

In the future, there is a gap between the universal demand for educational research data and the quality of data. In the process of empirical study of educational economics, from the past to the present development, the data content involved in the empirical study of China's education economics from the macro state development, to the middle and micro individual aspects. With the continuous development of Internet technology and information technology, big data information has provided more data and data for educational economics research. However, the education data 
information used in our country is only a small part of the extensive research topics in the future. It is an important challenge to improve the quality of data and to increase the amount of data information.

From the present perspective, there may be imbalances between educational economics in China in exploring problems and new research methods. In the future development, the increasing number of research topics can help researchers to choose more space in the process of choosing research topics. At the same time, the application of analytical technology is too easy to produce empirical and formalistic empirical phenomena. In many cases, researchers do research topics for new research methods, ignoring the real purpose of the research, not emphasizing the value of the issue, and putting the cart before the horse. Therefore, it is a challenge that the economics of education will face in the future, how to effectively avoid this research, explore the theoretical value of the research, and improve the quality of the research.

The advent of the era of big data has a certain impact on all walks of life. It is inevitable that big data will bring more research topics to the traditional educational economics, and provide new research direction and research perspective. However, there is still a distance between the application of big data in education and the effective application of big data. For educational economics, the mass data and information of big data is not the real role. The traditional method of data research is different from that of large data. The research methods of large data have certain accuracy, the logic of statistical test, the representativeness of the research object and the generalization of the research conclusions, all of which are different from the traditional data analysis methods. Therefore, when facing the new big data, the researchers are too concerned about what the big data is and how to solve the fundamental problem. In the era of big data, it is an important challenge for the researchers of educational economics to apply large and traditional data rationally and effectively. It is a problem that how to make reasonable cooperation between the two.

In the future education, the issues of research are becoming more and more rich, and the problems of many researchers' cognitive limitations and resource limitations will become more and more prominent, and the contacts between domestic and international colleagues, researchers and managers will become more and more closely. Therefore, in the future of the development of educational economics, it is very important for researchers to keep their initial heart in the process of improving their cognitive level, and to study more valuable issues. How to maintain an objective and independent position is also a very challenging problem for the development of education economics in China [4].

\section{The Future Prospects and Development Measures of China's Educational Economics.}

First, in the new era, education economics can help our society to solve the development of middle income, and rely on science and technology and educational development to promote the sustainable development of the country. After entering the middle level of per capita income, China needs to accelerate the transformation of the economic development mode and optimize the industrial structure, so as to provide a certain motive force and vitality for the economic growth, thus promoting the healthy and effective development of our country's economy. However, the economic growth is only a superficial phenomenon in the middle income trap. The more serious consequence is the increasing contradiction between income and distribution, the deterioration of the economic situation, the increasing gap between the rich and the poor, and even the polarization of economic development. Therefore, in the future, how to promote the healthy and sustainable development of the economy and improve the situation between income and distribution in our country is a key research content. As a result, it is of great significance for the economic and social development of our country to improve the pertinence, scientificity, and effectiveness of the economics of education, and to play a real role and play a real role[5].

Second, innovation will be an important driving force for talent development, economic development and social development. Judging from the current situation, China will be an important period of economic structural transformation and industrial structure optimization and upgrading in the coming period. On the one hand, educational economics needs to study the 
production process of innovation, the law of innovation and the cultivation of talent innovation and so on, so that the content of these related aspects will be studied in depth. On the other hand, educational economics should deepen the research on economic structure and industrial structure. With the modernization of our country's economy and society and the continuous optimization and upgrading of the industrial structure, it is necessary to upgrade the structure of human resources in an all-round way, not only to expand the scale of talents, to upgrade the structure of talents, but also to constantly change the training mode of talents. At the same time, with the rapid development of Internet technology and modern information technology, the form of many industries has been remolded, so many new economic growth points have been produced in the educational field, which is a content worthy of high attention and research in education economics.

Third, the significance of educational economics research in promoting the building of a well-off society in an all-round way. Under the strategic goal of building a well-off society in an all-round way, the status and role of education is very important. In the process of strengthening social construction, China should pay attention to the realization of other powers and interests while realizing people's economic power. For the harmonious development of the society, the people's life is peaceful and peaceful, the education should give full play to its own function and function, and what role and how to realize it need to carry on the important research. At the same time, with the continuous development of urbanization, the relationship between new urbanization and education needs important research. In the process of urbanization, the distribution and change law of the educational population, the adjustment of the layout of the education space, the result of education and so on are all the problems that the researchers should pay more attention to.

Fourth, the economics of education is of great significance for enhancing China's international competitiveness. As the international ties become closer and closer, the level of China's participation in the governance of international affairs is becoming deeper and deeper. Therefore, this will urgently require more talented people with international competitiveness. In the context of advocating new globalization, with the development of China's prosperity and strength, its role in international affairs is becoming more and more important, and at the same time, it bears more responsibilities. From the point of view of the development, our country's education economics has not enough research on the international flow law of human resources or talents, the economic and social consequences and so on, and the content of the empirical study is less. Therefore, in the future development, the education economics of our country needs to face the development of the international society, and has already studied more issues in the international perspective, which will bring more practical analysis for the training of talents and the promotion of international competitiveness.

First, to expand and deepen the research content of educational economics. First of all, we need to refine the relationship between human capital investment and the reduction of inequality and the sustainable development of the economy. With the continuous exploration of educational economics, the relationship between the two efficiency and fairness can be solved scientifically so as to realize the practical value of educational resources. Secondly, we should make an in-depth study of educational choice. On the one hand, study the private choice of education. For example, whether students enter school, where schools are chosen, and teachers' career choices. On the other hand, we should study the contents of public choice. For example, the system and mechanism of education finance, as well as the system, how to choose and choose what kind of education policy and so on. Finally, on the basis of studying the short-term effect and long-term effect and the effect of education policy, the research on the evaluation of education policy further analyzes the mechanism of the function of education policy[6].

Second, the theory of educational economics should be further explored. First of all, the theory of educational economics should be deeply studied, and educational economics should be developed on the basis of understanding, enriching the theoretical connotation. On the one hand, the basic theory of education economics should be refined, including the content of the educational production function, the theory of human resources, the content of educational finance and the allocation of educational resources, the choice of education and the selection of schools, and so on, 
which need to be carefully understood and applied one by one. On the other hand, the theory of educational economics extends not only the basic theory but also the theoretical content. For example, political economics, information economics and so on, need scientific and systematic research. Whether it is the basic theory of education economics or the theory of expansion, we need to study deeply on the basis of understanding and grasp. Finally, we should build and expand the specific mode of education with the characteristics of our country. Secondly, educational economics should continue to integrate with related disciplines. In the course of development, educational economics should be integrated with related subject theories, for example, policy decisions in political science, social stratification in sociology and so on. The theoretical contents of these disciplines are likely to be interdisciplinary with educational economics. Finally, we should construct the educational economics theory with its own characteristics. The construction of educational economics with the characteristics of our country can better meet the needs of the social development of our country, effectively solve the problems and contradictions of our country, for example, the problem of return on education and the division of labor market, so that the theory of education economics is more pertinent and scientific, thus the sustainable development of our society. The exhibition provides a positive role.

Third, continue to strengthen and improve the empirical method of educational economics. In this process, data construction, data mining and data preparation should be carried out. We should focus on establishing more longitudinal tracking data, such as large scale and so on, and improve the measurement level of education and improve the quality of data information. When conducting social science research, the most important measure is random intervention test. At the same time, the micro econometric analysis method should be applied effectively to provide the most accurate and scientific method for the study of educational economics. In addition, the use of mixed research methods can promote the effective combination of qualitative and quantitative analysis, and provide a full range of empirical cases for the problems of educational economics research. Finally, we should continue to improve the quality of research and methodology. In the process of applying different methods, we can make accurate judgment and effective solution, make the research conclusion more scientific and rational, and improve the quality and level of the research results.

\section{Conclusion}

Education economics is an important subject, its research content is profound and the field is wide, which has a positive influence on the development of education and the development of economy and society. Although from the present point of view, there will be some challenges and difficulties in the development of education economics in China. If it is not effective to solve the positive response, the healthy development of education economics will be affected. However, with the continuous deepening of reform and innovation and development, China's education economics will be more vigorous on the road in the future, not only to improve the quality of education, and to bring more vitality to the educational world. At the same time, it can promote economic structure transformation, industrial structure optimization and upgrading, narrow the gap between the rich and the poor, and so on, to provide more positive role for the healthy and sustainable development of the economy and society, thus promoting the prosperity and prosperity of our country.

\section{References}

[1] Barton U A. Competing Visions of the Western International Economic Order and the Chinese Belt and Road Initiative: Challenges and Opportunities [J]. Social Science Electronic Publishing, 2018.

[2] LI Xue-shu, FAN Guo-rui. Global Educational Equity in the Future: Vision, Challenges and Reflection_-Based on Analysis of "Education 2030 Framework for Action" [J]. International \s\&lscomparative Education, 2016.

[3] Padhi S R. Overcoming Exclusion and Marginalization in Education through Inclusive 
Approaches: Challenges and Vision of Arunachal Pradesh in India [J]. 2017, 6(4):256-261.

[4] Johnson J. China's Vision of the Future Networked Battlefield: Emerging Military-Technological Challenges to the United States [J]. 2018.

[5] Ma B. On Russia's "Turning East" Strategy: Motives, Vision and Challenges [J]. Russian Studies, 2017.

[6] Norose T, Manabe T, Furuta S, et al. The Vision and Challenges of Hokkaido Pharmaceutical University's Affiliated Pharmacy [J]. Yakugaku Zasshi-journal of the Pharmaceutical Society of Japan, 2016, 136(5):727-731. 